\title{
Other Clinical Trial Submission Document
}

National Cancer Institute

\section{Source}

National Cancer Institute. Other Clinical Trial Submission Document. NCI Thesaurus. Code C126093.

A set of documents describing the trial or changes/updates to the trial submitted to a committee other than the IRB/IEC for approval. 